\title{
Characterization of Curcumin/Cyclodextrin Polymer Inclusion Complex and Investigation on Its Antioxidant and Antiproliferative Activities
}

\author{
Jianping Chen ${ }^{1,2}$, Xiaoming Qin ${ }^{1}$, Saiyi Zhong ${ }^{1}$, Suhua Chen ${ }^{1}$, Weiming Su ${ }^{1}$ and Ying Liu ${ }^{3, *}$ \\ 1 College of Food Science and Technology, Guangdong Ocean University, Guangdong Provincial Modern \\ Agricultural Science and Technology Innovation Center for Subtropical Fruit and Vegetable Processing, \\ Zhanjiang 524088, China; cjp516555989@126.com (J.C.); xiaoming0502@21cn.com (X.Q.); \\ zsylxc@126.com (S.Z.); cshh1111@126.com (S.C); hdsuwm@163.com (W.S.) \\ 2 Guangdong Province Key Laboratory for Green Processing of Natural Products and Product Safety, \\ Guangzhou 510640, China \\ 3 Faculty of Agricultural Science, Guangdong Ocean University, Zhanjiang 524088, China \\ * Correspondence: liuying85168@gdou.edu.cn; Tel.: +86-0759-238-3247
}

Received: 3 April 2018; Accepted: 14 May 2018; Published: 15 May 2018

\begin{abstract}
The aims of this study were to characterize the curcumin/cyclodextrin polymer inclusion complex using X-ray diffractometry (XRD), Fourier transform infrared spectroscopy (FTIR), differential scanning calorimetry (DSC), and UV-vis spectroscopy, and to determine the antioxidant activity of this complex by methods of scavenging 2,2-azinobis-3-ethylbenzothiazoline-6-sulfonic acid (ABTS) radicals assays and 1,1-diphenyl-2-picrylhydrazyl (DPPH) radicals assays. The inhibitory effect of inclusion complex on A375 cells was also investigated by CCK-8 assay, Annexin-V/PI staining assay, and caspase activity assay. The results showed that the complex exhibited different physicochemical characteristics from that of free curcumin. Moreover, the inclusion complex exhibited novel antioxidant activity by scavenging the ABTS and DPPH free radicals and displayed higher antiproliferative activity on A375 cells. Further investigation revealed that inclusion complex could induce A375 cell apoptosis. These findings suggest that inclusion complex could be developed as a novel natural antioxidant with potential applications in cancer chemoprevention.
\end{abstract}

Keywords: curcumin; $\beta$-cyclodextrin polymer; inclusion complex; antioxidant activity; anticancer activity

\section{Introduction}

Curcumin $\left(\mathrm{C}_{21} \mathrm{H}_{20} \mathrm{O}_{6}\right)$, a hydrophobic yellow-orange polyphenol derived from the rhizome of the herb Curcuma longa, has been widely used in food as a stabilizer in jellies or as a natural colorant in cheeses and in traditional medicine as an ingredient [1,2]. Additionally, curcumin has been shown to inhibit the growth and proliferation of variety of tumor cells [3,4]. However, the disadvantage of poor bioavailability and rapid metabolism of curcumin has restricted its application. Various techniques such as liposomes, nanocapsules, nanoparticles, and various derivatives of cyclodextrins have been tried to enhance curcumin delivery [5]. Among these methods, inclusion complexation with cyclodextrins and their derivatives are the most useful method to enhance the aqueous solubility of poorly water-soluble bioproducts [6].

Cyclodextrins (CDs) are cyclic oligomers of glucose that can form water-soluble inclusion complexes with small molecules or fragments of large compounds [7]. Nowadays, many studies on enhancement of solubility of curcumin with cyclodextrins have been reported. Although there are many studies of curcumin with CDs to enhance the guest's solubility $[2,8]$, the limited solubility of host CDs restrains the application of curcumin in water. Therefore, finding a high water-soluble 
host is a key to extensive applications of curcumin in aqueous phase. $\beta$-cyclodextrin polymer has been obtained by reaction of the parent $\beta$-cyclodextrin with a cross-linking agent, epichlorohydrin [9]. Especially, $\beta$-cyclodextrin polymer as a highly water-soluble polymer is well known to selectively form inclusion complexes. Zhang et al. have reported that $\beta$-cyclodextrin polymer was used as a host molecule to prepare hypericin/ $\beta$-cyclodextrin polymer inclusion complex to improve its aqueous solubility [10].

Therefore, in this article, the curcumin/ $\beta$-cyclodextrin polymer inclusion complex was prepared according to the previous method and evaluated the formation of the complexes using the FTIR, X-ray diffraction, DSC, and UV. Additionally, the antioxidant and antiproliferative activities of the formed complexes were further investigated.

\section{Results and Discussion}

\subsection{Physicochemical Characterization of Curcumin/Cyclodextrin Polymer Inclusion Complex}

\subsubsection{XRD Analysis}

The XRD spectra of curcumin, cyclodextrin polymer, their physical mixture and inclusion complex are shown in Figure 1. As shown in Figure 1, some sharp peaks at the diffraction angle of $2 \theta 7.83$, $8.78,9.8611 .99,13.76,15.79,17.13$, and 21.01 were present in the X-ray diffractogram of curcumin powder, suggesting that the powder exists in a crystalline form. The XRD pattern of cyclodextrin polymer showed two broad peaks in the ranges of $10-15^{\circ}$ and $15-20^{\circ}(2 \theta)$, confirming its amorphous characteristic in nature. The X-ray diffractogram of the physical mixture showed approximate superimposition of the individual patterns of both cyclodextrin polymer and curcumin. In the case of inclusion complex, the spectrum exhibits a new diffraction peak. Some sharp peaks originally found at the diffraction angles of $2 \theta 7.83,8.78,9.8611 .99,13.76,15.79,17.13$, and 21.01 in the curcumin samples disappeared or weakened, suggesting the formation of the inclusion complex.

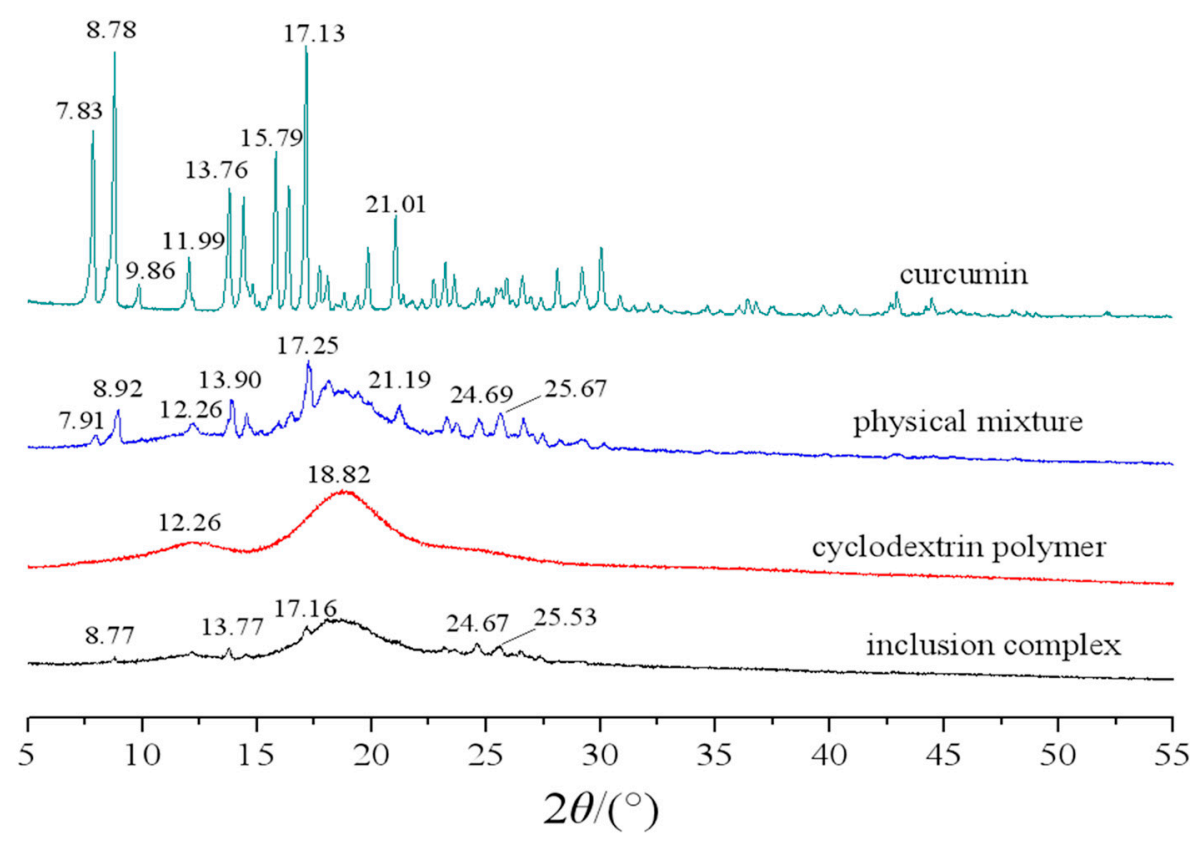

Figure 1. Powder X-ray diffraction patterns of curcumin, curcumin and cyclodextrin polymer physical mixture, cyclodextrin polymer, and curcumin/cyclodextrin polymer inclusion complex. 


\subsubsection{FTIR Analysis}

FTIR spectroscopy was used to ascertain the formation of the curcumin/cyclodextrin polymer inclusion complex. Figure 2 shows the FTIR spectra of curcumin, cyclodextrin polymer, their physical mixture and inclusion complex. The typical IR spectrum of curcumin was presented in Figure 2a, which was in good agreement with literature [11]. The FTIR spectrum of curcumin exhibits an absorption band at $3505 \mathrm{~cm}^{-1}$ indicate the presence of the phenolic $\mathrm{O}-\mathrm{H}$ stretching vibration. Additionally, stretching vibrations of benzene ring of curcumin at $1627 \mathrm{~cm}^{-1}$ and C-O and C-C vibrations of curcumin at $1510 \mathrm{~cm}^{-1}$ was exhibited in Figure 2a. The typical IR spectrum of cyclodextrin polymer was presented in Figure 2b, which was in good agreement with literature [12]. In Figure 2b, the bands observed at $3406 \mathrm{~cm}^{-1}$ and $2927 \mathrm{~cm}^{-1}$ are assigned to -OH stretching vibration and -CH2 anisomerous stretching vibration, respectively. The characteristic band observed at $1033 \mathrm{~cm}^{-1}$ is assigned to stretching vibration of C-O-C. All above absorption peaks can be found in physical mixtures of curcumin and cyclodextrin polymer (Figure 2c). However, all absorption peaks of cyclodextrin polymer can be found, but all characteristic peaks of curcumin almost disappear. Only a faint $\mathrm{C}-\mathrm{O}$ and C-C vibrations at $1511 \mathrm{~cm}^{-1}$ was observed (Figure 2d), which provides substantial evidence of the formation of curcumin/cyclodextrin polymer inclusion complex.

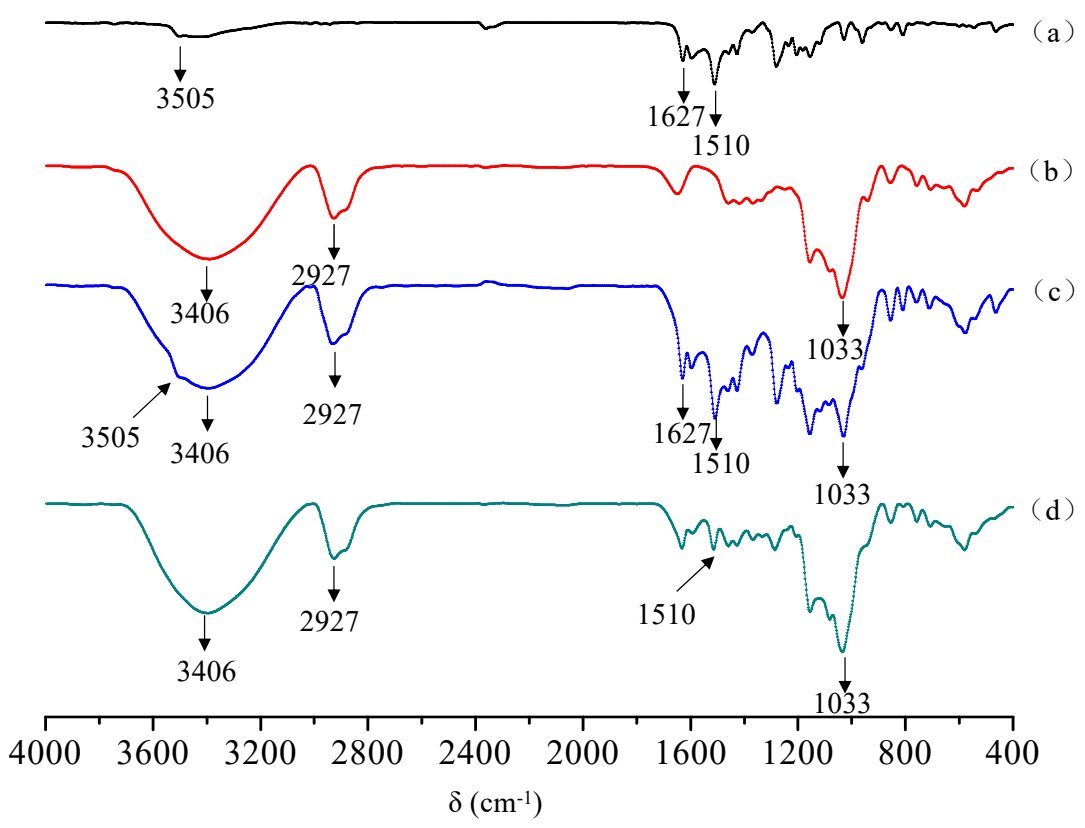

Figure 2. FTIR spectra of curcumin (a); cyclodextrin polymer (b); curcumin and cyclodextrin polymer physical mixture (c); curcumin/cyclodextrin polymer inclusion complex (d).

\subsubsection{DSC Analysis}

DSC curves of curcumin, cyclodextrin polymer, their physical mixture and inclusion complex were shown in Figure 3. Curcumin showed a sharp endothermic peak at $185.3^{\circ} \mathrm{C}$, corresponding to the melting point (Figure 3a). In contrast, the thermogram of cyclodextrin polymer did not present any peak in the region of $80-220^{\circ} \mathrm{C}$ (Figure $3 \mathrm{~b}$ ). The thermal profile of their physical mixture was apparently a combination of characteristics of curcumin and cyclodextrin polymer (Figure 3c). However, the DSC curve of their inclusion complex mainly showed features of cyclodextrin polymer, while the DSC characteristics of curcumin disappeared (Figure 3d). These data should confirm the formation of the inclusion complex. 


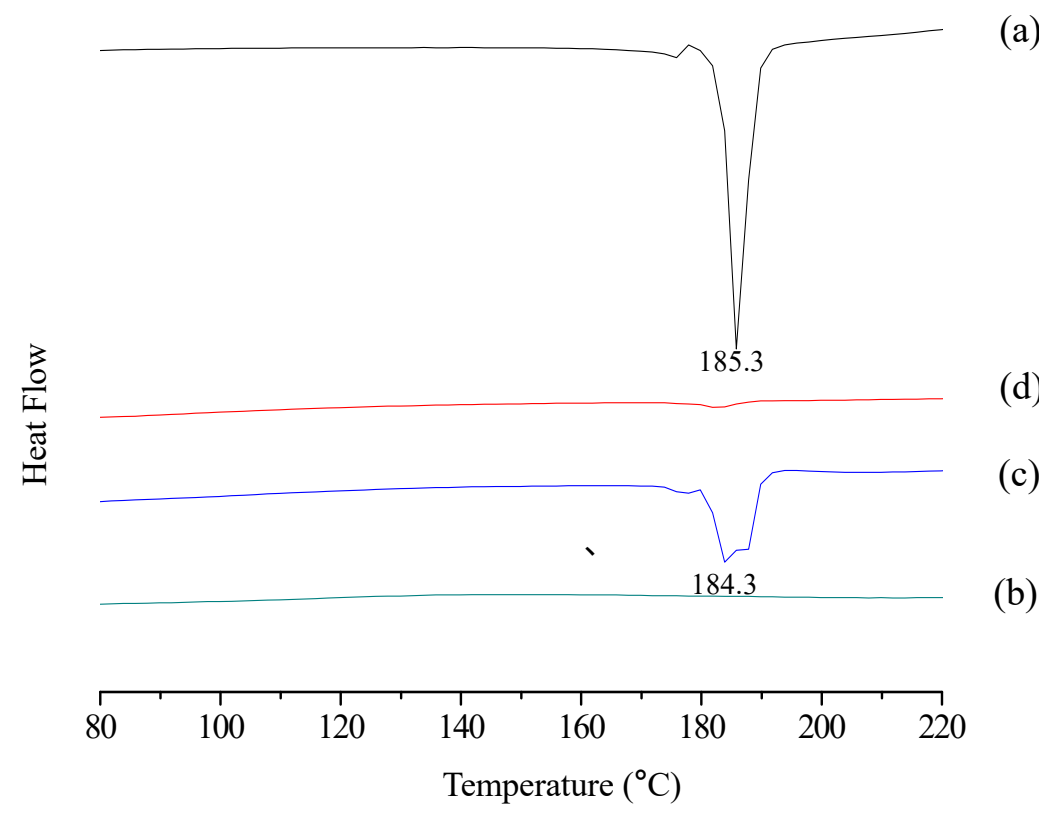

Figure 3. DSC thermograms of curcumin (a); cyclodextrin polymer (b); curcumin and cyclodextrin polymer physical mixture (c); curcumin/cyclodextrin polymer inclusion complex (d).

\subsubsection{UV Spectra Analysis}

UV spectra of curcumin/cyclodextrin polymer inclusion complexes and cyclodextrin polymer were shown in Figure 4. In Figure 4a, no absorption was observed for cyclodextrin polymer in the range of 300-600 nm, while the typical absorption peaks in the inclusion complex were observed in the range of 300-600 $\mathrm{nm}$ as shown in Figure $4 \mathrm{~b}$, which attributed to the absorption peak of curcumin. These results indicated that the inclusion complex was formed.

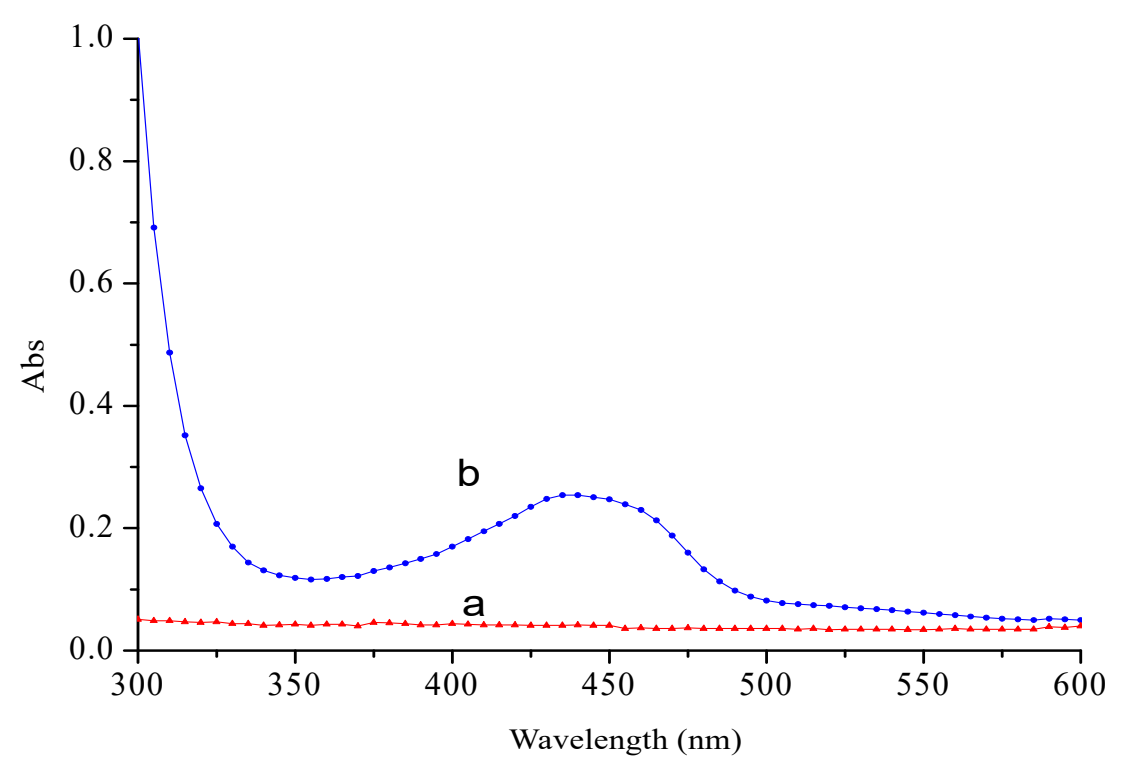

Figure 4. UV spectra of cyclodextrin polymer (a) and curcumin/cyclodextrin polymer inclusion complexes (b) at a wavelength of 300-600 $\mathrm{nm}$ at room temperature.

\subsection{Phase Solubility of Curcumin/Cyclodextrin Polymer Inclusion Complex}

Phase solubility analysis is very useful for investigating inclusion complexation of poorly soluble compounds with cyclodextrin polymer, because it gives not only the stoichiometry of curcumin/ 
cyclodextrin polymer inclusion complex but also the stability constant of the complexes by analyzing the solubility curve [13]. The phase solubility diagrams for curcumin/cyclodextrin polymer inclusion complex is shown in Figure 5, which displayed an AL-type according to Higuchi and Connors [14]. According to Higuchi and Connors' theory, the 1:1 stoichiometry of the inclusion complex was achieved from the initial ascending part of the curve, a nearly straight line with the slope of 0.9878 . The regression equation was

$$
\mathrm{Y}=0.9878 \mathrm{X}+0.4357, \mathrm{R}=0.9921
$$

where $\mathrm{Y}$ is the concentration $(\mathrm{M})$ of curcumin, $\mathrm{X}$ is the concentration $(\mathrm{M})$ of cyclodextrin polymer. The apparent stability constant $\mathrm{K}_{1: 1}$ was obtained to be $198 \mathrm{M}^{-1}$ according to Equation (1), which indicated that a sufficient interaction between curcumin and cyclodextrin polymer occurs.

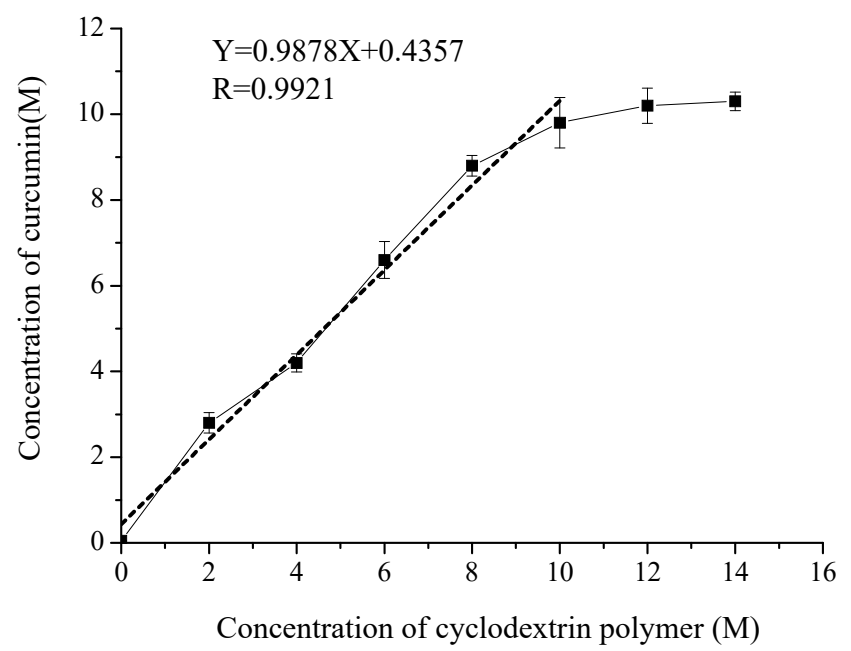

Figure 5. Phase solubility profile of curcumin/cyclodextrin polymer inclusion complex.

\subsection{In-Vitro Antioxidant Activity of Curcumin/Cyclodextrin Polymer Inclusion Complex}

The total antioxidant capacity of inclusion complex was evaluated by ABTS $\bullet+$ scavenging methods. The relatively long-lived ABTS•+, generated by the direct oxidation of ABTS with manganese dioxide, is decolorized during the reaction with hydrogen-donating antioxidants [15]. As shown in Figure $6 \mathrm{~A}$, the ABTS radical scavenging rate of curcumin was extremely low. However, comparing with curcumin, the ABTS radical scavenging rate of inclusion complex was significantly increased. With the concentration of inclusion complex increased, the ABTS radical scavenging rate of inclusion complex was increased from $5.28 \pm 0.21 \%(20 \mu \mathrm{g} / \mathrm{mL})$ to $47.79 \pm 0.91 \%(320 \mu \mathrm{g} / \mathrm{mL})$. Our results indicated that inclusion complex could effectively scavenge the ABTS free radical in a dose-dependent manner.

The DPPH method is used worldwide to quantify free radical scavenging activity. The method is based on the loss of color when the odd electron of the nitrogen atom in the DPPH radical is reduced by receiving a hydrogen atom from an antioxidant compound [16]. The antioxidant capacity of bioactive compounds can be modified in the presence of cyclodextrins. Therefore, the antioxidant activity of inclusion complex can be determined by monitoring the drop in absorbance by DPPH radical at $517 \mathrm{~nm}$. The DPPH radical scavenging activities of curcumin and inclusion complex are shown in Figure 6B. With the concentration of inclusion complex increased, the DPPH radical scavenging rate of inclusion complex was increased from $6.18 \pm 0.31 \%(20 \mu \mathrm{g} / \mathrm{mL})$ to $23.85 \pm 1.19 \%(320 \mu \mathrm{g} / \mathrm{mL})$. It showed that the scavenging activities of inclusion complex on DPPH radical were dose dependent. However, the scavenging activity of inclusion complex is lower than the curcumin. 


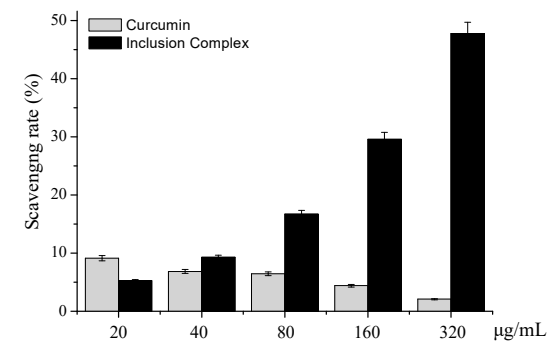

B

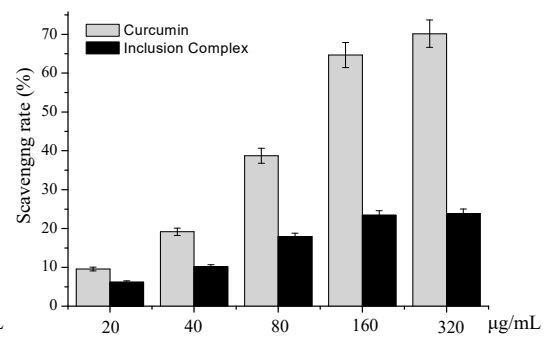

Figure 6. ABTS radical scavenging rate (A) and DPPH radical scavenging rate (B) of curcumin/ $\beta$-cyclodextrin polymer inclusion complex or curcumin with different concentrations. Values expressed are means \pm SD of triplicates.

\subsection{In-Vitro Anticancer Activity of Curcumin/Cyclodextrin Polymer Inclusion Complex}

\subsubsection{CCK-8 Assay}

The CCK-8 assay is a commonly used method to detect cell survival. To evaluate the cytotoxicity of inclusion complex, the A375, A549, HeLa, and MCF-7 cell lines were chosen to investigate the in vitro cytotoxicity of inclusion complex. The A375, A549, HeLa, and MCF-7 cell lines were exposed to various concentrations of inclusion complex $(40,80,160,320,640 \mu \mathrm{g} / \mathrm{mL})$ for $72 \mathrm{~h}$ followed by a CCK-8 assay. The results are shown in Table 1. As shown in Table 1, inclusion complex exhibited stronger inhibitory effects on $\mathrm{A} 375$ cells than other cancer cells, as shown by the $\mathrm{IC}_{50}$ values of $476.4 \mu \mathrm{g} / \mathrm{mL}$ for A375 cells, $517.2 \mu \mathrm{g} / \mathrm{mL}$ for A549, $545.7 \mu \mathrm{g} / \mathrm{mL}$ for Hela, $692.8 \mu \mathrm{g} / \mathrm{mL}$ for MCF-7. The A375 cells were selected to examine the antiproliferative activity of inclusion complex.

A

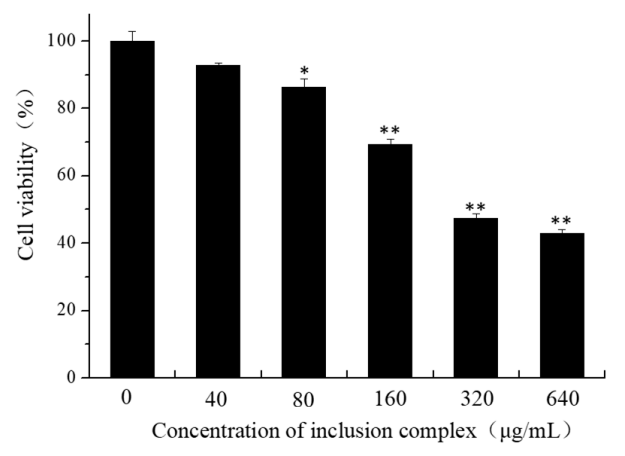

$\mathrm{B}$

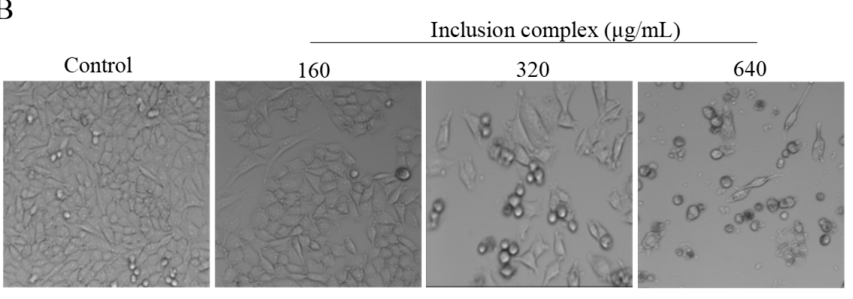

Figure 7. Effect of inclusion complex treatment for $72 \mathrm{~h}$ on cell viability of A375 cells. (A) Dose-dependent cytotoxic effects of inclusion on A375 cells. The cells were treated with different concentrations of inclusion complex and incubated for $72 \mathrm{~h}$. Cell viability was determined by the CCK- 8 assay. All data were obtained from three independent experiments are presented as the means \pm SD. $p<0.05\left(^{*}\right)$ or $p<0.01\left(^{* *}\right)$ vs. control group; (B) Morphological changes of A375 cells as examined by phase-contrast microscopy (magnification, $200 \times$ ). The images shown here are representative of three independent experiments with similar results. 
As shown in Figure 7A, the cell viability of A375 were in a dose dependent decrease with the concentration of inclusion complex ranging from 40 to $640 \mu \mathrm{g} / \mathrm{mL}$. After the A375 cell lines were respectively exposed to inclusion complex for $72 \mathrm{~h}$, the cell viability decreased from $92.7 \% \pm 0.9 \%$ at $40 \mu \mathrm{g} / \mathrm{mL}$ to $43.0 \pm 1.2 \%$ at $640 \mu \mathrm{g} / \mathrm{mL}$. Our results demonstrated that inclusion complex exhibited cytotoxic effects on the A375 cell lines. The morphological changes on A375 cells were attenuated by different concentrations of inclusion complex, given in Figure 7B. With increasing concentration of inclusion complex, the number of cells decreased gradually and the cells' morphology become round by comparison with control cells. This result was consistent with the detection of cell viability.

Table 1. $\mathrm{IC}_{50}$ of different cells exposed to curcumin/ $\beta$-cyclodextrin polymer inclusion complex for $72 \mathrm{~h}$.

\begin{tabular}{cc}
\hline Cells & IC $_{\mathbf{5 0}}(\boldsymbol{\mu g} / \mathrm{mL})$ \\
\hline A375 & 476.4 \\
A549 & 517.2 \\
Hela & 545.7 \\
MCF-7 & 692.8 \\
\hline
\end{tabular}

\subsubsection{Annexin V/PI Staining Assay}

Translocation of phosphatidylserine (PS) from the inner cellular membrane to the outer leaflet in the early stage of apoptosis has been identified as an important characteristic of apoptosis [17]. In order to further confirm that the cell death induced by inclusion complex was apoptosis, Annexin V/PI double staining was used to detect the extroversion of phosphatidyl serine on the cell membrane and the PI-specific stained cell nuclei after rupture of the membrane, indicating apoptosis. The results are shown in Figure 8. As shown in Figure 8, treatment of curcumin increased the percentage of apoptotic cells from $2.9 \%$ (control) to $16.0 \%(80 \mu \mathrm{g} / \mathrm{mL}), 21.4 \%(160 \mu \mathrm{g} / \mathrm{mL})$, and $25.7 \%(320 \mu \mathrm{g} / \mathrm{mL})$, respectively. However, compared with the treatment of curcumin, the inclusion complex significantly increased the cell apoptosis from $16.0 \%$ to $20.7 \%, 21.4 \%$ to $25.0 \%$, and $25.7 \%$ to $27.9 \%$, respectively. Our results indicated that inclusion complex promotes apoptosis on A375 cells in a dose-dependent manner.

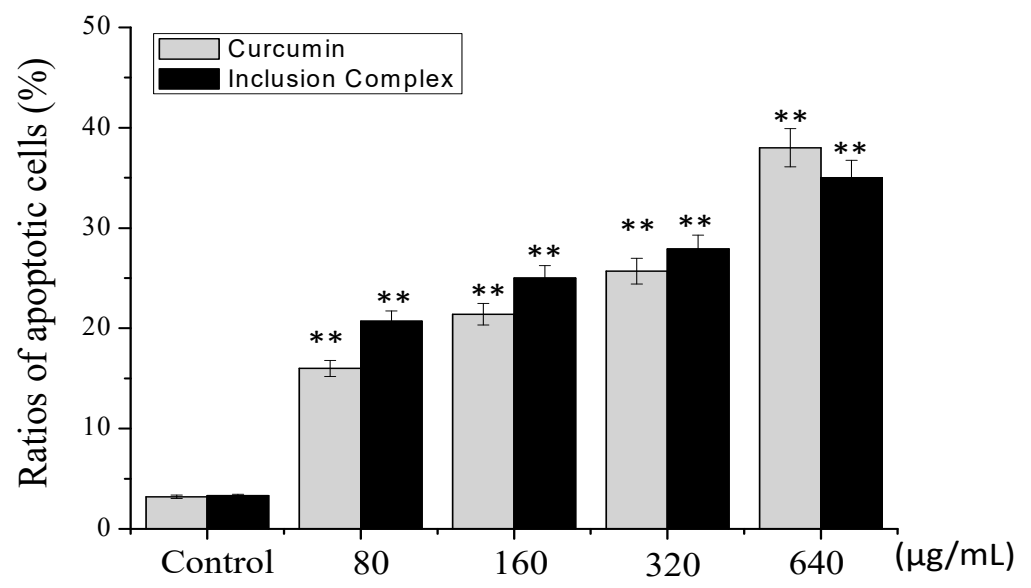

Figure 8. Flow cytometric analysis of A375 cells treated with inclusion complex by Annexin V/PI staining assay. $p<0.01\left({ }^{* *}\right)$ vs. control group.

\subsubsection{Caspase Activity}

According to the above experiments, inclusion complex induced the A375 cells apoptosis. However, the underlying mechanism was not clear. Many studies have shown that the two most important pathways were involved in inducing cell apoptosis including the death receptor-mediated extrinsic pathway and the mitochondria-mediated intrinsic pathway [18]. The caspase family members 
play a vital role in two central apoptotic pathways. Among them, caspase-8/9 acts as the initiator of the extrinsic and intrinsic pathways, respectively, whereas caspase- 3 is regarded as the central executioner of apoptosis [19]. To further confirm whether caspases-3/8/9 were involved in apoptosis, the activation of caspase-3/8/9 was analyzed by fluorometric assay. As shown in Figure 9 , treatment of inclusion complex increased the activation of caspase-3/8/9 to some extent. However, comparing with curcumin at $640 \mu \mathrm{g} / \mathrm{mL}$, inclusion complex decreased the activation of caspase-3/9 and increased the activation of caspase 8. Our results indicated that inclusion complex induced apoptosis in A375 cells though extrinsic and intrinsic apoptotic pathways.

A

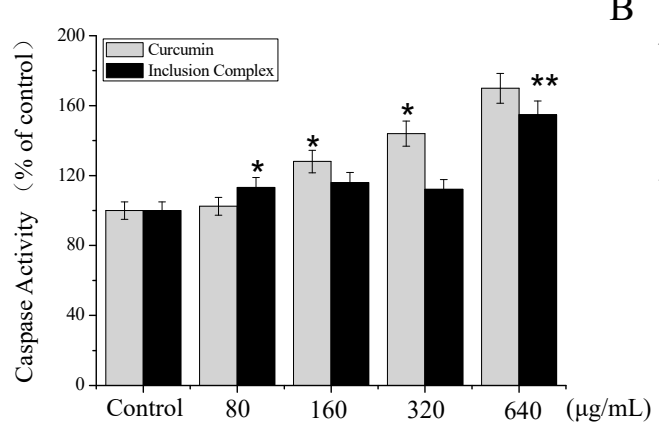

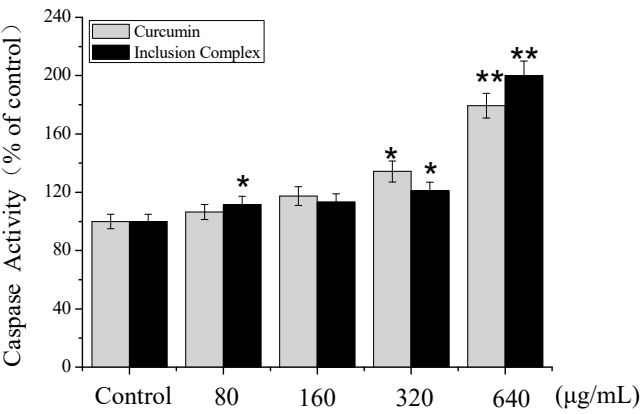

$\mathrm{C}$

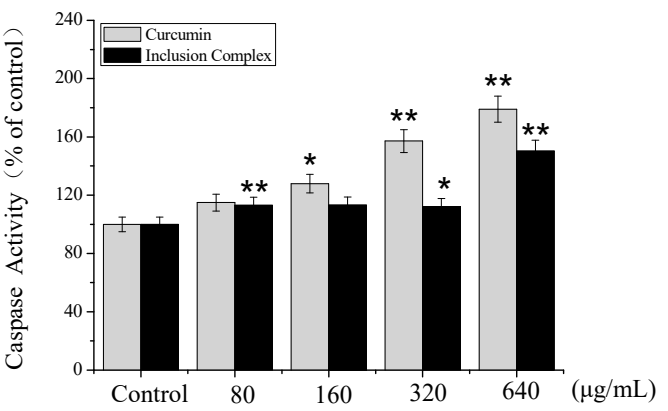

Figure 9. Effects of inclusion complex on caspase activities of caspase $3(\mathbf{A})$, caspase $8(\mathbf{B})$, and caspase 9 (C) in A375 cells. Caspase activities as measured by specific fluorescent substrates for caspase-3/8/9. Cells were pretreated with different concentrations of inclusion complex or curcumin for $72 \mathrm{~h}$, respectively. Significant difference between treatment groups and control groups is indicated at $p<0.05\left(^{*}\right)$ or $\left.p<0.01{ }^{* *}\right)$ level.

\section{Materials and Methods}

\subsection{Materials}

Curcumin, ABTS (2,2'-azinobis-3-ethylbenzothiazolin-6-sulfonic acid), and DPPH (1,1'-diphenyl2-picryhydrazyl) were obtained from Sigma-Aldrich (Sigma-Aldrich, St. Louis, MO, USA). $\beta-C D$ (chemical purity) was purchased from Shangdong Xinda Biotechnology Co., Ltd. (Zibo, China). Epichlorohydrin (EP) and ethylene glycol were purchased from Sinopharm Chemical Reagent Co., Ltd. (Shanghai, China). RPMI 1640 medium were purchased from Hyclone Company (South Logan, UT, USA). Fetal bovine serum (FBS) and the antibiotic mixture (penicillin-streptomycin) were purchased from Gibco Company (Grand Island, NY, USA). Cell Counting Kit-8 (CCK-8) was purchased from Dojindo Company (Kumamoto, Japan). Caspase 3 assay kit (ab39401), Caspase 8 assay kit (ab39700), and Caspase 9 assay kit (ab65608) were purchased from Abcam Company (Cambridge, UK). Annexin V/PI apoptosis kit were purchased from MultiScience Company (Hangzhou, China). Sodium hydroxide and other reagents were of analytical grade and were purchased from Nanjing Chemical Reagent Co. Ltd. (Nanjing, China). Double distilled and sterilized water was used to prepare all solutions. 


\subsection{Preparation of Cyclodextrin Polymer and Curcumin/Cyclodextrin Polymer Inclusion Complex}

Cyclodextrin polymer was synthesized by cross-linking $\beta$-CD with EP under a strongly alkaline condition $(33 \mathrm{wt} \% \mathrm{NaOH})$. The molar ratio of $\beta-\mathrm{CD} / \mathrm{EP}$ was $1: 7$. The details of the synthesis and purification were shown as in the reference [9].

The preparation of the inclusion complex of curcumin with cyclodextrin polymer was shown as follow: briefly, $4 \mathrm{~g}$ cyclodextrin polymer and $1 \mathrm{~g}$ curcumin was mixed together by a spatula in the mortar, then dissolved in $50 \mathrm{~mL}$ of distilled water. The resultant mixture was treated by SB-3200 ultrasonic (Xinzhi Biotechnology, Ningbo, China) for $5 \mathrm{~min}$, then sufficiently stirred for at least $48 \mathrm{~h}$ at room temperature. At the end of the reaction, the final solution was recovered by filtration to remove the residual curcumin. Then, the inclusion complex was obtained by pressure distillation, and it was dried in a vacuum oven at $60^{\circ} \mathrm{C}$ for $48 \mathrm{~h}$.

\subsection{Preparation of Curcumin and Cyclodextrin Polymer Physical Mixture}

Cyclodextrin polymer was pulverized in ceramic mortars. The calculated amounts of curcumin and cyclodextrin polymer with a mass ratio of 1:4 were mixed together by a spatula until a homogeneous mixture was obtained.

\subsection{Physicochemical Characterization}

\subsubsection{Fourier Transform Infrared Spectroscopy (FTIR)}

The FTIR spectra of curcumin, cyclodextrin polymer, their physical mixture, and the inclusion complex were obtained using a Tensor 27 fourier transform infrared spectroscopy (Bruker, Karlsruhe, Germany) with 256 scans at a resolution of $4 \mathrm{~cm}^{-2}$. The scanning range was 4000 and $400 \mathrm{~cm}^{-1}$. The samples were ground with spectroscopic grade potassium bromide $(\mathrm{KBr})$ powder and pellets were made to perform the measurements.

\subsubsection{X-ray Diffractometry (XRD)}

The X-ray diffraction was recorded using D8 ADVANCE diffractometer (Bruker, Germany), operated at a voltage of $40 \mathrm{KV}$ and a current of $40 \mathrm{~mA}$. The samples were investigated in the $2 \theta$ angle range of $5-55^{\circ}$ and the process parameters were set as: scan step size of $0.02^{\circ}$, scan step time of $17.7 \mathrm{~s}$.

\subsubsection{Differential Scanning Calorimetry (DSC)}

DSC curves of curcmin, cyclodextrin polymer, the physical mixture and the inclusion complex were analyzed by a STA449F3 simultaneous thermal analyzer (Netzsch, Bavaria, Germany). Each sample $(2-5 \mathrm{mg})$ was heated in a sealed aluminum pan at a rate of $10{ }^{\circ} \mathrm{C} / \mathrm{min}$ from 80 to $220^{\circ} \mathrm{C}$ under a nitrogen flow of $30 \mathrm{~mL} / \mathrm{min}$. An empty sealed pan was used as the reference.

\subsubsection{UV Analysis}

$10 \mathrm{mg}$ of cyclodextrin polymer and inclusion complex were diluted in $100 \mathrm{~mL}$ of water, respectively. They were scanned using an Evolution 300 UV-vis spectrophotometer (Thermo Scientific, Waltham, MA, USA) at a wavelength of 300-600 $\mathrm{nm}$ at room temperature.

\subsection{Phase Solubility Study}

Phase solubility analysis was carried out according to the method reported by Higuchi and Connors [14]. Briefly, an excess amount of curcumin was added into $10 \mathrm{~mL}$ of cyclodextrin polymer aqueous solutions with various concentrations (2-14 mol/L). Then all the samples were then shaken at $(25 \pm 2){ }^{\circ} \mathrm{C}$ for $48 \mathrm{~h}$. After equilibrium was reached, the mixtures were withdrawn and filtered through $0.45 \mu \mathrm{m}$ membrane filter and properly diluted. The concentration of curcumin in each filtrate was determined by a high performance liquid chromatography (HPLC). The apparent complexation 
constant (Kc) for complexation could be calculated from the phase solubility diagrams, according to the following equation (Equation (1)): $K c=$ slope $/ S_{0}(1-$ slope).

Where $S_{0}$ is the intrinsic solubility of curcumin in deionized water in the absence of cyclodextrin polymer and slope is the slope of the straight line.

\subsection{HPLC Analysis}

Curcumin $(12.25 \mathrm{mg})$ was dissolved in methanol (100 mL). Then $0.2,0.4,0.6,0.8,1.6,2.4,3.2$, and $5.0 \mathrm{~mL}$ solution were taken out and diluted to $10 \mathrm{~mL}$ with mobile phase, respectively. These samples were analyzed by a Waters HPLC system (Waters $2695 \mathrm{~N}$, Milford, MA, USA) with methanol $-1 \%$ citric acid $(70: 30, v / v)$ as the mobile phase. The flow rate of mobile phase was $1 \mathrm{~mL} / \mathrm{min}$. $10 \mu \mathrm{L}$ samples were separated on a Scienhome Kromasil C18 column $(4.6 \times 150 \mathrm{~mm}, 5 \mu \mathrm{m})$ and detected at $425 \mathrm{~nm}$. According to the calibration curve: $\mathrm{Y}=102211 \mathrm{X}-256580, \mathrm{R}=0.9940$, the concentration of curcumin was calibrated, and a good linearity was observed in the range of $2.45-49 \mu \mathrm{g} / \mathrm{mL}$.

\subsection{Antioxidant Activities of Curcumin/Cyclodextrin Polymer Inclusion Complex}

\subsubsection{ABTS+ Free Radical Scavenging Assay}

According to previous research methods by Miller et al. [20], $5 \mathrm{mM}$ ABTS stock solution in PBS ( $\mathrm{pH}$ 7.4) and the right amount of $\mathrm{MnO}_{2}$ were mixed until full reaction. Then the solution was filtrated by $0.2 \mu \mathrm{M}$ PVDF syringe filter and diluted with $5 \mathrm{mM}$ phosphate-buffered saline (PBS) buffer (pH 7.4) appropriately to obtain ABTS reaction solution (an absorbance of 0.70 at $734 \mathrm{~nm}$ recorded on a Varioskan Flash multimode reader). In the reaction system, $180 \mu \mathrm{L}$ ABTS reaction solution and $20 \mu \mathrm{L}$ samples were added to 96-well plates. After mixing for $5 \mathrm{~min}$, the absorbance of mixture was measured at $734 \mathrm{~nm}$ using a Varioskan Flash multimode reader (Thermo Fisher Scientific, USA) with room temperature in the dark.

\subsubsection{Scavenging Activity of DPPH+ Free Radical}

According to methods of previous study by Okada and Okada [21], a certain amount of DPPH was dissolved in methanol to obtain a stock solution of DPPH $(6 \mathrm{mM})$, stored at $-20^{\circ} \mathrm{C}$ in the dark. The solution was diluted with methanol to a final concentration of $60 \mu \mathrm{M}$ before using. In the reaction system, $180 \mu \mathrm{L}$ DPPH reagent and $20 \mu \mathrm{L}$ samples were added to 96-well plates, mixed, and shocked for $5 \mathrm{~min}$. The absorbance was recorded at $515 \mathrm{~nm}$ by Varioskan Flash microplate reader (Thermo Fisher Scientific, USA) until the reading was stable. This experiment was carried out at room temperature in the dark.

\subsection{Evaluation of Cytotoxic Activity of Curcumin/Cyclodextrin Polymer Inclusion Complex}

\subsubsection{Cell Culture}

A375 melanoma cell line, A549 lung carcinoma cell line, HeLa cervical carcinoma cell line and MCF-7 breast adenocarcinoma cell line were purchased from American Type Culture Collection (ATCC, Manassas, VA, USA). The cell lines were grown in RPMI-1640 medium supplemented with $10 \%$ fetal bovine serum, 100 units $/ \mathrm{mL}$ penicillin, and 50 units $/ \mathrm{mL}$ streptomycin at $37^{\circ} \mathrm{C}$ in a humidified ( $5 \% \mathrm{CO}_{2}, 95 \%$ air) atmosphere.

\subsubsection{Cell Viability Assay}

Cell viability assay was analyzed using Cell Counting Kit (CCK-8; Dojindo Laboratories, Kumamoto, Japan) assay in accordance with the manufacturer's protocol. Briefly, cells were seeded into 96-well culture plates $\left(1 \times 10^{4}\right.$ cells/well $)$ and then cultured at $37^{\circ} \mathrm{C}$ under saturated humidity incubator $\left(5 \% \mathrm{CO}_{2}, 95 \%\right.$ air) for $24 \mathrm{~h}$. The cells were treated with inclusion complex at different concentrations for $72 \mathrm{~h}$. After incubation, the medium in the 96-well plate was replaced with fresh 
medium, and $10 \mu \mathrm{L}$ CCK-8 working fluid was added to each well. After a $4 \mathrm{~h}$ culture in the incubator, the optical density (OD) value (absorbance) was measured at $450 \mathrm{~nm}$ by a microplate spectrophotometer (Multiskan, MK3). All experiments were performed in quadruple on three separate occasions.

\subsubsection{Annexin-V/PI Staining Assay}

We used an Annexin V/PI apoptosis kit from MultiScience Company (Hangzhou, China) to detect cell apoptosis induced by inclusion complex as previously described [22]. In brief, following the kit instructions, A375 cells were treated with inclusion complex or curcumin at different concentrations for $72 \mathrm{~h}$. After reaching the specified time, the cells were trypsinized, collected by centrifugation at $1000 \mathrm{rpm}$ for $5 \mathrm{~min}$ and washed twice with PBS. The cells were resuspended in $500 \mu \mathrm{L}$ binding buffer and stained with $5 \mu \mathrm{L}$ Annexin V-FITC and $10 \mu \mathrm{L}$ PI for $15 \mathrm{~min}$ at room temperature in darkness. Samples was analyzed by flow cytometry (BD FACScalibur Flow Cytometer, BD Biosciences) $(\mathrm{Ex}=488 \mathrm{~nm}, \mathrm{Em}=530 \mathrm{~nm})$.

\subsubsection{Caspase Activity Assay}

Caspase-3, -8, and -9 activities were determined using the caspase-3/8/9 assay kit (Abcam) according to the manufacturer's instructions. In brief, the A375 cells were exposed with inclusion complex or curcumin at different concentrations for $72 \mathrm{~h}$. After reaching the specified time, the A375 cells were suspended in $50 \mu \mathrm{L}$ of chilled cell lysis buffer and incubated cells on ice for $20 \mathrm{~min}$. The mixtures were centrifuged at $10,000 \times g$ for $1 \mathrm{~min}$, then the supernatants were collected and the total protein concentration was measured immediately by BCA kit. After that, cell lysates were added to the 96-well plates (every well containing an equal amount of protein) and $50 \mu \mathrm{L}$ of $2 \times$ Reaction Buffer (containing $0.5 \mu \mathrm{L}$ of $10 \mathrm{mM}$ DTT) was added to each sample. Then, $5 \mu \mathrm{L}$ of the Caspase- 3 substrate (DEVD-p-NA), Caspase-8 substrate (IETD-p-NA), Caspase-9 substrate (LEHD-p-NA) were added, and incubated at $37^{\circ} \mathrm{C}$ for $2 \mathrm{~h}$. The samples were measured at $405 \mathrm{~nm}$ using a Multiskan MK3 microplate reader (Thermo Fisher Scientific, USA). The fluorescence intensity of the treated samples was compared with that of control samples to determine the fold-increase in caspase activity.

\subsection{Statistical Analysis}

The obtained data were expressed as the mean \pm standard deviation of triplicate determinations. Statistical analysis was performed using the SPSS statistical package (SPSS 13.0 for Windows; SPSS, Inc., Chicago, IL, USA).

\section{Conclusions}

In this study, the results of XRD, FTIR, DSC, and UV showed that curcumin/cyclodextrin polymer inclusion complex had different physicochemical characteristics from free curcumin. After the formation of inclusion complex, the complex exhibited novel antioxidant and anti-cancer activities.

Author Contributions: Conceived and designed the experiment: J.C. and Y.L.; Performed the experiments: J.C. and S.C.; Analyzed the data: J.C. and S.C.; Contributed regents/materials/analysis tools: X.Q., S.Z., W.S. and Y.L.; Wrote the paper: J.C. and Y.L.

Acknowledgments: This work was supported by the National Natural Science Foundation of China (no. 21602034), Natural Science Foundation of Guangdong Province (no. 2016A30310332), Open Foundation of Guangdong Province Key Laboratory for Green Processing of Natural Products and Product Safety (no. 201617), and the Scientific Research Foundation of Guangdong Ocean University (no. R17034).

Conflicts of Interest: The authors declare no conflict of interest. 


\section{References}

1. Chen, X.; Zou, L.Q.; Niu, J.; Liu, W.; Peng, S.F.; Liu, C.M. The stability, sustained release and cellular antioxidant activity of curcumin nanoliposomes. Molecules 2015, 20, 14293-14311. [CrossRef] [PubMed]

2. Mangolim, C.S.; Moriwaki, C.; Nogueira, A.C.; Sato, F.; Baesso, M.L.; Neto, A.M.; Matioli, G. Curcumin-beta-cyclodextrin inclusion complex: Stability, solubility, characterisation by FTIR, FT-Raman, X-ray diffraction and photoacoustic spectroscopy, and food application. Food Chem. 2014, 153, 361-370. [CrossRef] [PubMed]

3. Ravindran, J.; Subbaraju, G.V.; Ramani, M.V.; Sung, B.Y.; Aggarwal, B.B. Bisdemethylcurcumin and structurally related hispolon analogues of curcumin exhibit enhanced prooxidant, anti-proliferative and anti-inflammatory activities in vitro. Biochem. Pharmacol. 2010, 79, 1658-1666. [CrossRef] [PubMed]

4. Dandawate, P.R.; Vyas, A.; Ahmad, A.; Banerjee, S.; Deshpande, J.; Swamy, K.V.; Jamadar, A.; Dumhe-Klaire, A.C.; Padhye, S.; Sarkar, F.H. Inclusion complex of novel curcumin analogue CDF and beta-cyclodextrin (1:2) and its enhanced in vivo anticancer activity against pancreatic cancer. Pharm. Res-Dordr. 2012, 29, 1775-1786. [CrossRef] [PubMed]

5. Mohamed, S.A.; El-Shishtawy, R.M.; Al-Bar, O.A.M.; Al-Najada, A.R. Chemical modification of curcumin: Solubility and antioxidant capacity. Int. J. Food Prop. 2017, 20, 718-724. [CrossRef]

6. Song, X.; Wen, Y.T.; Zhu, J.L.; Zhao, F.; Zhang, Z.X.; Li, J. Thermoresponsive Delivery of Paclitaxel by beta-Cyclodextrin-Based Poly(N-isopropylacrylamide) Star Polymer via Inclusion Complexation. Biomacromolecules 2016, 17, 3957-3963. [CrossRef] [PubMed]

7. Wei, Y.; Zhang, J.; Zhou, Y.; Bei, W.; Li, Y.; Yuan, Q.; Liang, H. Characterization of glabridin/ hydroxypropyl-beta-cyclodextrin inclusion complex with robust solubility and enhanced bioactivity. Carbohydr. Polym. 2017, 159, 152-160. [CrossRef] [PubMed]

8. Marcolino, V.A.; Zanin, G.M.; Durrant, L.R.; Benassi, M.D.T.; Matioli, G. Interaction of curcumin and bixin with beta-cyclodextrin: Complexation methods, stability, and applications in food. J. Agric. Food Chem. 2011, 59, 3348-3357. [CrossRef] [PubMed]

9. Zhang, W.; Chen, M.; Diao, G.W. Preparation and electrochemical behavior of water-soluble inclusion complex of ferrocene with beta-cyclodextrin polymer. Electrochim. Acta 2011, 56, 5129-5136. [CrossRef]

10. Zhang, W.; Gong, X.; Cai, Y.; Zhang, C.; Yu, X.; Fan, J.; Diao, G. Investigation of water-soluble inclusion complex of hypericin with beta-cyclodextrin polymer. Carbohydr. Polym. 2013, 95, 366-370. [CrossRef] [PubMed]

11. Cutrignelli, A.; Lopedota, A.; Denora, N.; Iacobazzi, R.M.; Fanizza, E.; Laquintana, V.; Perrone, M.; Maggi, V.; Franco, M. A new complex of curcumin with sulfobutylether-beta-cyclodextrin: Characterization studies and in vitro evaluation of cytotoxic and antioxidant activity on HepG-2 Cells. J. Pharm. Sci-Us 2014, 103, 3932-3940. [CrossRef] [PubMed]

12. Chen, M.; Wang, J.Q.; Zhang, W.; Diao, G.W. Preparation and characterization water-soluble inclusion complexes of imidacloprid-beta-cyclodextrin polymer and their electrochemical behavior. J. Electroanal. Chem. 2013, 696, 1-8. [CrossRef]

13. Su, J.Y.; Chen, J.P.; Li, L.; Li, B.; Shi, L.; Zhang, H.M.; Ding, X. Preparation of natural borneol/ 2-hydroxypropyl- $\beta$-cyclodextrin inclusion complex and its effect on the absorption of tetramethylpyrazine phosphate in mouse. Chem. Pharm. Bull. 2012, 60, 736-742. [CrossRef] [PubMed]

14. Higuchi, T.; Connors, K.A. Phase solubility technique. Adv. Anal. Chem. Instrum. 1965, 4, 117-212.

15. Leong, L.P.; Shui, G. An investigation of antioxidant capacity of fruits in Singapore markets. Food Chem. 2002, 76, 69-75. [CrossRef]

16. Scherer, R.; Godoy, H.T. Antioxidant activity index (AAi) by the 2,2-diphenyl-1-picrylhydrazyl method. Food Chem. 2009, 112, 654-658. [CrossRef]

17. Yu, B.; Zhang, Y.B.; Zheng, W.J.; Fan, C.D.; Chen, T.F. Positive surface charge enhances selective cellular uptake and anticancer efficacy of selenium nanoparticles. Inorg. Chem. 2012, 51, 8956-8963. [CrossRef] [PubMed]

18. Long, S.; Wilson, M.; Bengten, E.; Clem, L.W.; Miller, N.W.; Chinchar, V.G. Identification and characterization of a FasL-like protein and cDNAs encoding the channel catfish death-inducing signaling complex. Immunogenetics 2004, 56, 518-530. [CrossRef] [PubMed] 
19. Li, Y.H.; Li, X.L.; Zheng, W.J.; Fan, C.D.; Zhang, Y.B.; Chen, T.F. Functionalized selenium nanoparticles with nephroprotective activity, the important roles of ROS mediated signaling pathways. J. Mater. Chem. B 2013, 1, 6365-6372. [CrossRef]

20. Miller, N.J.; Sampson, J.; Candeias, L.P.; Bramley, P.M.; Rice-Evans, C.A. Antioxidant activities of carotenes and xanthophylls. FEBS Lett. 1996, 384, 240-242. [CrossRef]

21. Okada, Y.; Okada, M. Scavenging effect of water soluble proteins in broad beans on free radicals and active oxygen species. J. Agric. Food Chem. 1998, 46, 401-406. [CrossRef] [PubMed]

22. Zhang, Y.B.; Li, X.L.; Huang, Z.; Zheng, W.J.; Fan, C.D.; Chen, T.F. Enhancement of cell permeabilization apoptosis-inducing activity of selenium nanoparticles by ATP surface decoration. Nanomedicine 2013, 9, 74-84. [CrossRef] [PubMed]

Sample Availability: Samples of the compounds cyclodextrin polymer are available from the authors.

(C) 2018 by the authors. Licensee MDPI, Basel, Switzerland. This article is an open access article distributed under the terms and conditions of the Creative Commons Attribution (CC BY) license (http:/ / creativecommons.org/licenses/by/4.0/). 